\title{
An analysis of Knowledge of Sexual and Reproductive Health among Adolescents and Young persons Living with HIV: The case of Chitungwiza, Harare, Zimbabwe
}

\author{
Lianora Manyange ${ }^{1 *}$, Norman Makunika Chulalongkorn ${ }^{2}$ \\ ${ }^{1}$ University of Zimbabwe Center for Population Studies \\ ${ }^{2}$ University College of Population Studies
}

*Corresponding Author: Lianora Manyange, University of Zimbabwe Center for Population Studies.

Received date: October 06, 2021; Accepted date: October 25, 2021; Published date: October 29, 2021

Citation: Lianora Manyange, Norman Makunika Chulalongkorn (2021) An analysis of Knowledge of Sexual and Reproductive Health among Adolescents and Young persons Living with HIV: The case of Chitungwiza, Harare, Zimbabwe. J. Women Health Care and Issues. 4(8); DOI:10.31579/2642-9756/091

Copyright: () 2021 Lianora Manyange, This is an open access article distributed under the Creative Commons Attribution License, which permits unrestricted use, distribution, and reproduction in any medium, provided the original work is properly cited.

\begin{abstract}
It has been decades into the HIV pandemic, the position of the disease has advanced significantly from death sentence to a chronically manageable disease that can be lived with for long time. This evolution was made possible with the advent of antiretroviral therapy which allowed HIV infected children to reach adulthood. However, sexual, and reproductive needs of these generations remain unattended in many countries. The study sought to highlight the sexual and reproductive health issues affecting young people living with HIV in Chitungwiza and Waterfalls communities, targeting HIV positive young people aged 15-24 years. A mixed methods approach was adopted in which, Qualitative and Quantitative research methods were employed. A survey was conducted with 113 young people to quantify sexual and reproductive health issues affecting young people living with HIV (YPLWH). To solicitate community perceptions and opinions on childbearing among the Adolescents and Young persons living with HIV, 8 focus group discussions and key informant interviews were conducted to qualify the data from the survey. The findings indicated that sexual and reproductive health (SRH) knowledge heavily impacts YPLWH'. Socio-cultural barriers are major inhibiting factors limiting YPLWH. The study recommends that academic research, NGOs, and other stakeholders with support from the Ministry of Health, should conduct more studies on emerging HIV and SRH issues which will help in addressing knowledge gaps and provide evidence-based knowledge in public health. Overall, this will improve the reproductive health outcomes of young people living with HIV.
\end{abstract}

Key words: reproductive; HIV; SRH

\section{Introduction}

Zimbabwe National Adolescent and Youth Sexual and Reproductive Health Strategy (2016-2020) highlighted that the provision of sexual and reproductive health services, including education was consistently concentrated on adults and high-risk groups leaving out the entire population including young people. This exclusion of young people in $\mathrm{SRH}$ issues is a problem among adolescents and young people in general, and a double jeopardy to YPLWH. As a result, young people living with HIV persistently face challenges in managing sexual relationships, safer sexual behaviour, access and utilisation of contraceptives and decisions on childbearing. Thus, this research seeks to investigate Sexual and reproductive issues among adolescents and young persons living with HIV.

\section{Objectives}

Specific Objectives:

I. Examine the knowledge of sexual and reproductive health among adolescents and young persons living with HIV

II. Assess the behavior and practices of young people living with HIV pertaining to Sexual and Reproductive Health. 


\section{Methodology and Study Design}

The study was carried out in Waterfalls and St Mary's districts of Chitungwiza in Harare Province. Currently, Chitungwiza is one of the suburbs with a high HIV prevalence of $8.4 \%$ whereas Waterfalls constitute a moderately low prevalence of $6 \%$ (ZNAC, 2015) against a national prevalence of $13.3 \%$ (Global Aids Response Progress Report 2017). Waterfalls is a medium density suburb while St Mary's is a highdensity residential community. These two areas were selected because they are urban areas with YPLWH from low income and middle-income backgrounds.

\section{Target Population}

The target population was young people living with HIV aged between 15-24 years. Fifteen years was set as minimum age because young people become sexually active around age fifteen. The maximum age was set at 24 years because the maximum age for one to qualify to be a young adult is 24 years (WHO, 2015; UNFPA, 2004:2016).

\section{Study design}

The study triangulated qualitative and quantitative research methods. Focus group discussions (FGDs), key informant interviews (KIIs) and indepth interviews were used to gather qualitative data. A survey was carried out so as to collect quantitative data. Qualitative data was analyzed using thematic analysis, whilst quantitative data was analyzed using descriptive statistics. The respective methods are discussed in detail below.

\section{Data Collection Methods and Tools}

\section{Survey}

A survey was carried out using a questionnaire. The questionnaire was designed drawing from the most outstanding issues defined in FGDs. A survey was carried out so as to quantify the salient sexual and reproductive health issues faced by young people living with HIV. A survey also quantified the accessibility, affordability and utilization of SRH services in St Mary's and Waterfalls by YPLWH respectively

\section{Sample size determination}

The sample size (n) was calculated using the formula:

$\mathrm{n}=\left(\mathrm{Z}^{2} \mathrm{pq}\right) / \mathrm{e}^{2}$

$\begin{array}{ll}\mathbf{n}= & \text { the desired sample size; } \\ \mathbf{Z}^{2}=\quad \begin{array}{l}\text { standard error set at (1.96) } \\ \text { corresponds to } 95 \% \text { confidence }\end{array} & \begin{array}{c}\text { which normally } \\ \text { interval; }\end{array}\end{array}$

$\mathbf{p}=$ proportion of YPLWH (15 to 24 years) to the population in the two surburbs;
$\mathbf{q}=$
the proportion of total population of young people who are not HIV positive in both suburbs.
$\mathrm{e}^{2}=$ sampling error set at (0.0495)

The calculated sample size was 113 respondents.

\section{Sampling frame}

The sampling frame was composed of four health centers working directly with SOS Children's Villages in St Mary's (3) and Waterfalls (1). Thus, the sampling frame comprised a list of Waterfalls and St Mary's Clinic registers for YPLWHIV. YPLWH aged between $15-24$ years with at least 6 months of stay in the two communities were primarily targeted. Hence, the researcher had to randomly select the participants from the list.

\section{Sampling Procedure}

The sampling design constituted four stages. Health centers were purposively selected targeting the four centers which are supported by SOS Children's Villages. There are three healthcare centers in St Mary's and one Waterfalls which work in partnership with SOS Children's Villages Zimbabwe in administering ARVs and delivery of SRH services for young people (FSP Manual; 2017). Thus, the clinics were purposively selected. The second stage involved getting client registers for YPLWH aged between 15 and 24 years. Each name on the register list was assigned a number and randomly selected. In order to ensure representation of respondents, probability proportional to size (PPS) sampling was applied. Respondents selected per center are shown in Table 1.

\begin{tabular}{|c|c|c|c|c|c|}
\hline \multirow[b]{2}{*}{ Age Group } & \multicolumn{4}{|c|}{$\begin{array}{l}\text { Population of YPLWH Per Health Care } \\
\text { Center }\end{array}$} & \multirow[b]{2}{*}{ Total } \\
\hline & 1 & 2 & 3 & 4 & \\
\hline $15-17$ & 60 & 100 & 41 & 51 & 252 \\
\hline $18-20$ & 16 & 22 & 56 & 27 & 121 \\
\hline $21-24$ & 59 & 82 & 112 & 127 & 380 \\
\hline Total Population of YPLWH & 135 & 204 & 209 & 205 & 753 \\
\hline Sample per Healthcare Center & 20 & 31 & 31 & 31 & 113 \\
\hline
\end{tabular}

Table1: Distribution of YPLWH in St Mary's and Waterfalls per Age Group and per Healthcare Center

\section{Training of enumerators and pretesting}

A training session with four enumerators was done. The training focused on the purpose of the study, methodology, clarity and familiarization with the questionnaire. During the training, clarification of every question and optional responses was done. This was important to ensure consistency in data collection. After the training session, the research instrument was pre-tested in St Mary's Ward 5, a ward which has similar socio-economic characteristics with wards that were targeted for the study. Finally, a debriefing meeting highlighting errors in the questionnaire was held. Respective questions were corrected and finalized.

\section{Focus Group Discussions (FGDs)}

The study conducted 8 FGDs using a focus group discussion guide. FGDs were conducted with YPLWH aged between 15 and 24 years. Factors of homogeneity and heterogeneity were considered during the process of selecting participants. Participants were selected basing on the following age cohorts 15-17 years, 18-20 years, 21-24 years in Waterfalls and Chitungwiza respectively. In each age group respondents who were not involved in the survey were selected. FGDs were undertaken so as to examine group generated attitudes about the salient sexual reproductive health issues faced by YPLWH in St Mary's and Waterfalls. FGDs were also undertaken so as to assess group generated perceptions about the accessibility, affordability and utilization of SRH services by YPLWH. Convenience sampling was used to select the FGDs participants so as to eliminate wrong targeting and minimize bias. All the FDGs in St Mary's were carried out at St Mary's Community Hall close to St Mary's Clinic where YPLWH usually come for their support groups and collection of antiretroviral drugs (ARVs). A facilitator who is the author of this research facilitated each FGD discussion in the vernacular language, 
while a trained research assistant took notes. The discussions were also tape recorded.

\section{Key Informant Interviews}

Eight face to face key-informant interviews using a key informant guide were conducted. They were carried out with two key informants from each of the following categories: Community Adolescents Treatment Supporter (CATs), Nurses, SOS Children's Villages Zimbabwe and Doctors operating in St Mary's Chitungwiza and Waterfalls. Heads in the respective groups were selected based on their experience and knowledge in SRH and HIV programming particularly dealing with adolescents and young people. Therefore, in-depth interviews with these stakeholders were done using a key informant guide to obtain their views on major SRH issues affecting young people living with HIV. In addition, KIIs provide important recommendations of the study. The data from KIIs was collected through note taking and audio recording.

\section{Data Management and Analysis}

The questionnaires used to conduct the survey were given codes before data collection. All the quantitative data collected was entered, cleaned, and analyzed using statistical package for social sciences (SPSS). A univariate analysis was used to quantify YPLWH's awareness and attitudes. Cross -tabulations were used to test basic relationship and a chisquare test was used to evaluate the strength of relationships between the variables. The $\mathrm{p}$-value of $<0.05$ was considered as statistically significant. Qualitative data was captured through note-taking and audio recording. The data was numbered, transcribed, coded and analyzed using thematic analysis. During the process of thematic analysis, six steps were undertaken. Firstly, familiarization with the data was done through listening to recordings and re-reading the transcripts. The second procedure involved generation of initial codes. The third step involved the selection of themes and sub-themes. The fifth stage involved the defining and naming of potential sub-themes. Finally, the sixth step involved generating a report relating to the research question. However, data were reported in a used complementary fashion.

\section{Ethical considerations}

The following offices namely; University of Zimbabwe's Center of Population Studies, District Administrator (DA) of Waterfalls as well as DA Chitungwiza approved the study to be carried out.

In order to get informed consent from the participants, the researcher explained the purpose of the study to the respondents. Potential risks and benefits of the study were also explained in vernacular Shona language. Participants were told that the benefits of the study were indirect since the study was intended to inform program designing, policy making or policy review. Again, such information would then be used as evidence-based data to assist the improvement of reproductive health delivery for YPLWH. Anonymity was ensured using coded questionnaires without names. The researcher also explained to the participants that the information obtained from the study was going to be kept confidentially by placing protected passwords on software data, while hardware data was going to be kept in lockable metal filing cabinets. After this, participants voluntarily agreed to take part in the study. At the end of the discussions, respondents were asked if they had any pertinent questions. Each responded signed a consent form before responding to the interviews.

\section{Conceptual Framework}

The study adapted the Ecological Model by McLeroy et al (1988). The framework assumes that sexual and reproductive health issues are affected by various factors at individual, interpersonal, community and institutional levels. At individual level, the model highlighted that chief driver of need for sexual and reproductive health include knowledge, age, sex, marital status, level of education and level of income. At interpersonal level attributes like peer pressure, cultural and religious norms and beliefs affect knowledge, sexual behavior and practices. Existing legal environment also impacts access to SRH services, acquisition of knowledge as well as sexual behavior.

Firstly, at individual level, the model assumed that age has a positive effect on sexual and reproductive health. For instance, as age increases, sexual activities also increase and so is the desire for SRH knowledge and the uptake of contraceptives. Therefore, the assumption is that if SRH education starts at primary level, young people would be more knowledgeable about SRH as they grow up. Again, the model assumed that marital status has direct effect on knowledge. When people are married, they need family planning services hence their desire to know more about pregnancy, contraceptives and childbearing will also increase.

There is a direct association between level of education, knowledge, access, and utilization of health services. As level of education increases, SRH knowledge also increase and attitude towards SRH is more likely to be positive, resulting to increased uptake of available SRH services. Other intermediate variables linked to education includes employment and income level. It is expected that when young people are educated, they are more likely to get employment and better income which enable them to access and afford other modern SRH services of their choice. On the other hand, if young people are not educated, they are less likely to get employment and sustainable income resulting in them not affording some modern SRH services. Also, the model assumed level of education has influence in decision making. If young people living with HIV are education, they are more likely to make independent and informed decision regarding their reproductive health. Contrary to that, people with no education are more likely to have poor decision making and poor sex negotiation skills.

At the second level, the model assumes a positive relationship between communication of sero-status to sexual partners and good outcomes of SRH. For instance, the assumption is that if YPLWH communicate their HIV status to their partners they are more likely to take preventive measures when they are having sex. Awareness of partners' status increase the probability of using condoms. The model assumes that status disclosure and effective communication may reduce domestic violence among married people or those in sexual relationship. The model predicts that that when HIV positive young people disclose their status they are more likely to get psychological support resulting in their utilization of SRH services.

At the third level, the model assume that societal beliefs have direct influence on sexual and reproductive health behavior. Childbearing, and sexual intercourse is assumed to occur within marriages or unions. This means there is stigma on unmarried people who access SRH services before they are married or in union, hence unmarried young people are less likely to access SRH services in fear of stigma. Since young people are engaging in pre-marital sex, the communities should be educated on the use of SRH among unmarried young people.

Further, the model assumed a positive relationship between religion, knowledge, sexual behavior and childbearing. Religion doctrine and cultural values directly influence attitude and practice. As church and culture continue to resist that young people are involving in premarital sex, their communication on SRH issues will always isolate young people and cultivate negative attitude towards SRH services among young people living with HIV. Further, the belief that talking about sex is a taboo will also continue to distance parents from educating their children on SRH issues. There is high risk that unmarried young people may have negative attitude towards SRH services.

In the fourth level, the model assume that service delivery system has direct influence on SRH outcome for YPLWH. The quality and standards 
of youth friendly facilities may attract HIV positive young people or vis versa. Also, the culture of health workers: confidentiality, friendliness and non-stigma attitude can attract HIV positive young people to visit health facilities for SRH services.
Finally, the model predicts that the legal requirements such as parental/spousal consent, has influence on access and utilization of SRH services. For instance, too many protocols involved in accessing SRH services reduces confidentiality which may drive away young people. The model assumes that if spousal consent is exempted for YPLWH, they are more likely to access and utilize available SRH services.

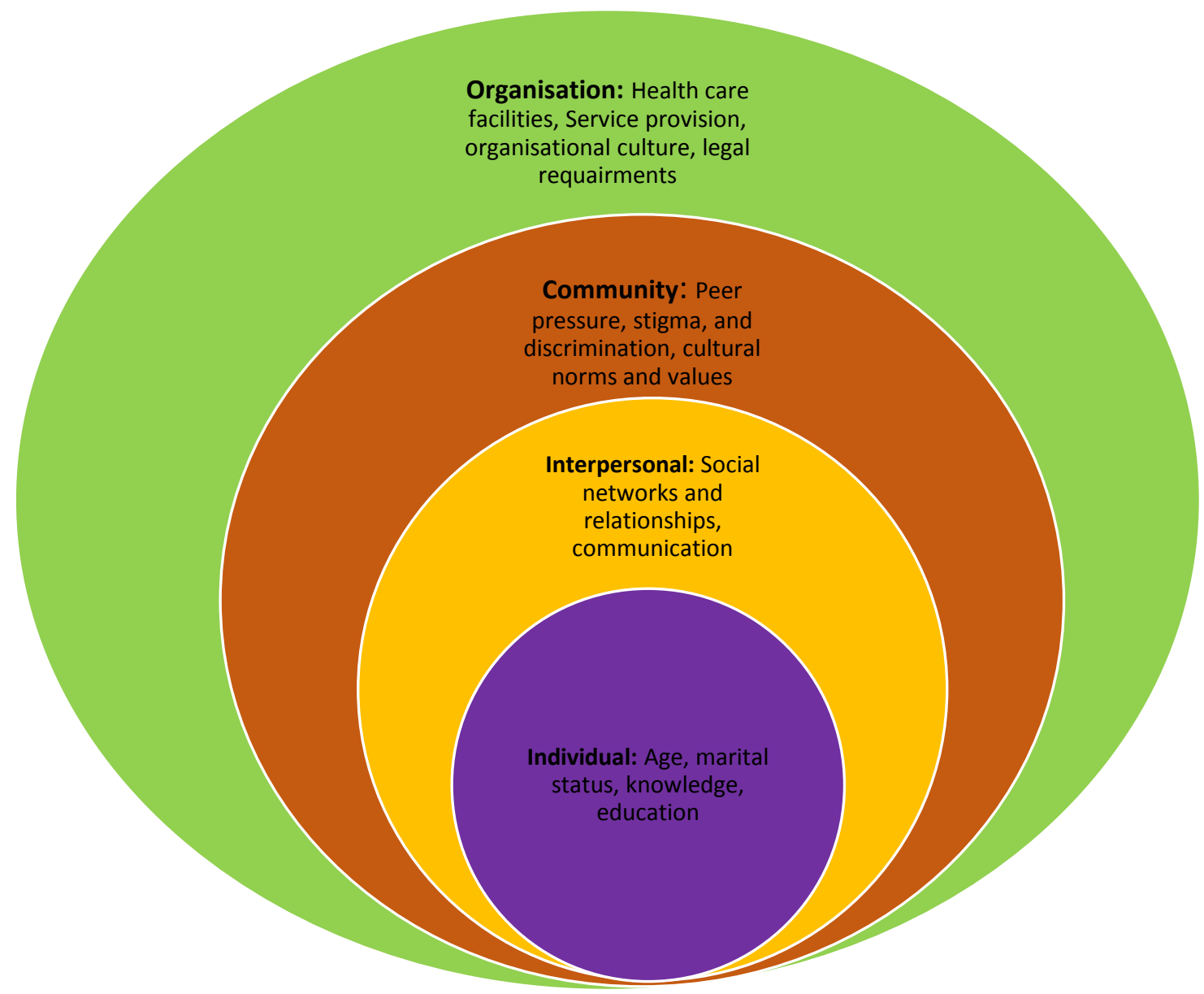

\section{Research Findings}

Knowledge about SRH was considered as an important issue among YPLWH. The key question on SRH knowledge was whether respondent's knowledge about sexual and reproductive health. The findings observed that less than half, $47 \%$, had sexual and reproductive health knowledge (Table 2). A correlation was observed between knowledge and age $(\mathrm{p}=0.011)$. Further analysis observed that as age increases, SRH awareness also increases. For instance, while $49 \%$ of the respondents aged between 21 and 24 years reported that they had knowledge about sexual and reproductive health, only $21 \%$, respondents aged between 15 and 17 years reported the same. Qualitative data revealed that older ages are more likely to have exposure to sexual activities than younger ages, hence the level of knowledge is also higher. This was supported by one of the young girls who gave her remarks in an FGD with the support from other participants:

"I became more interested to know about sexual and reproductive health when 1 was seventeen, after having sex with my boyfriend. We were all not prepared for pregnancy then someone told us about the emergency pill”
It was also revealed that young people who got infected in their infancy stage had limited knowledge about SRH. While $50 \%$ of respondents who got infected in their teenage, reported knowledge about SRH, only 38\% of those infected at infancy reported the same. Findings from the qualitative data shows that caregivers do not disclose HIV status to those who are born positive until they reach to their teenage. This affects even their attitude towards understanding HIV and SRH issues. A young man from the Waterfalls FGD remarked at the ululation of others:

"I was born HIV positive, why do you want me to be educated if the system failed to educate my mother to prevent me from HIV infection..."

It is observed that females were more likely, $54 \%$, to report knowledge of $\mathrm{SRH}$ than their male counterparts, $41 \%$. This gender differential in knowledge is also significant (0.002). Again, positive relationship between marriage and knowledge is also observed $(\mathrm{p}=0.041)$. For instance, while $53 \%$ of married/cohabiting reported knowledge of SRH, only $45 \%$, never married reported the same. During FGDs, there was a consensus that the community assumes that unmarried young people are not sexually active, and it is not acceptable to teach unmarried young people about sex issues. Hence, at community level, schools and churches also contributed to the exclusion of YPLWH accessing appropriate sexual 
and reproductive health education. One of the key informants from a local school had the following remark:

"I cannot be seen teaching my children about sex in class, knowing that soon after school they will go and experiment what 1 have been teaching them. It is better not to expose them to such knowledge at younger ages..."

The relationship observed between religion and knowledge of SRH was also significant $(\mathrm{p}=0.032)$. Results indicated that participants from Pentecostal, Mainline and Catholic demonstrated knowledge, 54\%, 55\% and $52 \%$ respectively. It is interesting to note that low SRH knowledge was reported among Apostolic, Muslims and African Tradition, 34\%, $29 \%$ and 20\% respectively. During the FGDs it was revealed that Muslim and African Tradition believed that their god is the god of fertility, life and death there is no need to be educated about reproductive health. They have their own educators as a doctrine practice where elders are the ones who teach young people about marriage. Such doctrine direct affect knowledge on SRH. The following remark was noted during an interview with a religious leader from the Apostolic church:

"My daughter, God speaks to us in everything, 1 do not need my child to be educated with a health worker. How can an unbeliever educate a believer, we believe the Holy Spirit informs us in all life issues including sexual and reproductive health issues? We have spirit led teachers who educate our young ones on how to live a holy life..." (Female KII; Waterfalls)

Further, qualitative findings revealed that although churches do not want to be seen at the forefront of educating people about SRH, there has been a move towards partnership with community health organization in raising awareness in church on topical health issues including HIV, reproductive health, and other health issues. One female participant during the FGD for 21-24 women remarked with support of others:

"This year our pastor declared May as a month of good health where health specialists were invited to educate different groups on specific health issues and in the youth female group we were educated about sex

\begin{tabular}{|lcc}
\hline Background Variable & Percentage & P-Value \\
Age & 21.2 & 0.011 \\
$15-17$ & 33.2 & \\
$18-20$ & 49.0 & 0.020 \\
$21-24$ & 37.9 & \\
Age at HIV infection & 49.6 & 0.002 \\
At infancy & & \\
At teenage & 54.2 & 0.041 \\
Sex & 41.3 & \\
Female & & \\
Male & 53.1 & 0.032 \\
Marital Status & 45.2 & \\
Married/Cohabiting & 51.5 & \\
Never Married & 50.1 & \\
Widowed & & \\
Divorced & 54.3 & \\
Religion & 55.0 & \\
Pentecostal & 52.2 & \\
Mainline & 34.1 & \\
Catholic & 29.3 & \\
Apostolic & 19.6 & \\
Muslims & 13.2 & \\
African Tradition & 32.3 & \\
Level of Education & 49.3 & \\
None & 52.7 & \\
Primary Education & & \\
Secondary Education & & \\
High School Education & &
\end{tabular}

and sexuality" (Female FGD, Waterfalls)

The analysis showed a significant relationship between education level and SRH knowledge $(\mathrm{p}=0.000)$. For instance, while $56 \%$ respondents with tertiary education had SRH knowledge, only $13 \%$ of those with no education reported the same. However, it was clear from the FGDs that youth with higher education are also motivated to look for information. Note this remark from a respondent who had university degree:

"Because 1 am HIV positive, 1 always want to catch up with current HIV trends so that 1 keep improving my quality of life" (Female respondent; Chitungwiza)

On the other hand, those with no education demonstrated low SRH knowledge, $32 \%$. Analysis from qualitative data revealed that because of lack of proper understanding, YPLWH with no education rely on other people for information regarding their reproductive health. One male respondent from the male FGD (21-24 years) expressed his views with support from other as follows:

"My wife is the one who attend HIV workshops and collect ARVs for us, as a man 1 cannot be seen attending these workshops and queuing for medication with women at clinic, those are women duties. My duty is to work and provide for the family...." (Male respondents; Chitungwiza)

The study noted that there was a significant association between SRH knowledge and employment status $(\mathrm{p}=0.020)$. For instance, $82 \%$, formally employed reported having SRH knowledge, $60 \%$ who were in the informal sector had SRH knowledge while only $29 \%$ of those not employed reported the same. This can be attributed to the exposure at workplace through trainings, access to internet and other educative materials found in a work environment. During an FGD, participants clapped hands in agreement with a young man who gave the following remark:

"I did not about long-acting contraceptive method until 1 attended a workshop on SRH at work, now 1 know where to get help if 1 need" (Male participant; Waterfalls). 


\begin{tabular}{|lll|}
\hline Tertiary & 55.5 & 0.021 \\
Employment & 50.6 & \\
Formally employed & 13.1 & \\
Domestic job & 30.5 & $0.251(\mathrm{NS})$ \\
Informally employed & 9.5 & \\
Unemployed & & \\
Income & 30.0 & \\
Less than $\$ 100$ & 36.3 & \\
\$101 to 250 & 38.4 & \\
\$251 to $\$ 500$ & 33.1 & \\
Above $\$ 500$ & 47.7 & \\
Total & & \\
\hline
\end{tabular}

\section{$\mathrm{N}=\mathbf{1 1 3}$}

Table 2: Percent distribution of respondents' knowledge on SRH by background variables

\section{Sources of Information and communication}

The study observed that source of information on SRH has an impact accuracy and quality of knowledge. In this study, the three major sources of SRH information for YPLWH were friends/peers (32\%), school (27) and social media $23 \%$ (Fig1). Ideally, health workers and parents are expected to take the lead in educating these young people. However, findings revealed that about $4 \%$ reported getting information from health workers and only $2 \%$ were getting information from their parents. Findings from the qualitative data revealed that information from peers and social media is not always accurate and maybe harmful to the health of YPLWH. Note the following remark from a young man in an FGD (1517 years) and he was supported by others:

"My friends always say that if you have unprotected sex with a person with albinism you will be cured of HIV" (Female Informant, Chitungwiza)

In another FGD in St Mary's, participants expressed their discomfort from getting information from health professionals indicating that the age gap makes the relationship more complicated. One of the FGD participants expressed the following, with support from other participants:

"Most health workers are of our parents' ages or even older, how can 1 discuss about sex and be able to fully express myself" (Female participant, Waterfalls)

Female focus group discussion revealed that stigma from health workers stop them from accessing information from the health centers. Common findings pointed to the poor packaging of message communicated to YPLWH during their counselling session. Note a remark from one young lady during FGD and other group members clapped their hands in agreement:

"Health workers always advise us to delay sex or abstain, but not many of us are able to do that. We hardly get information on safe sex from them; hence our peers and social media are the most convenient sources" (Female participant; FGD)

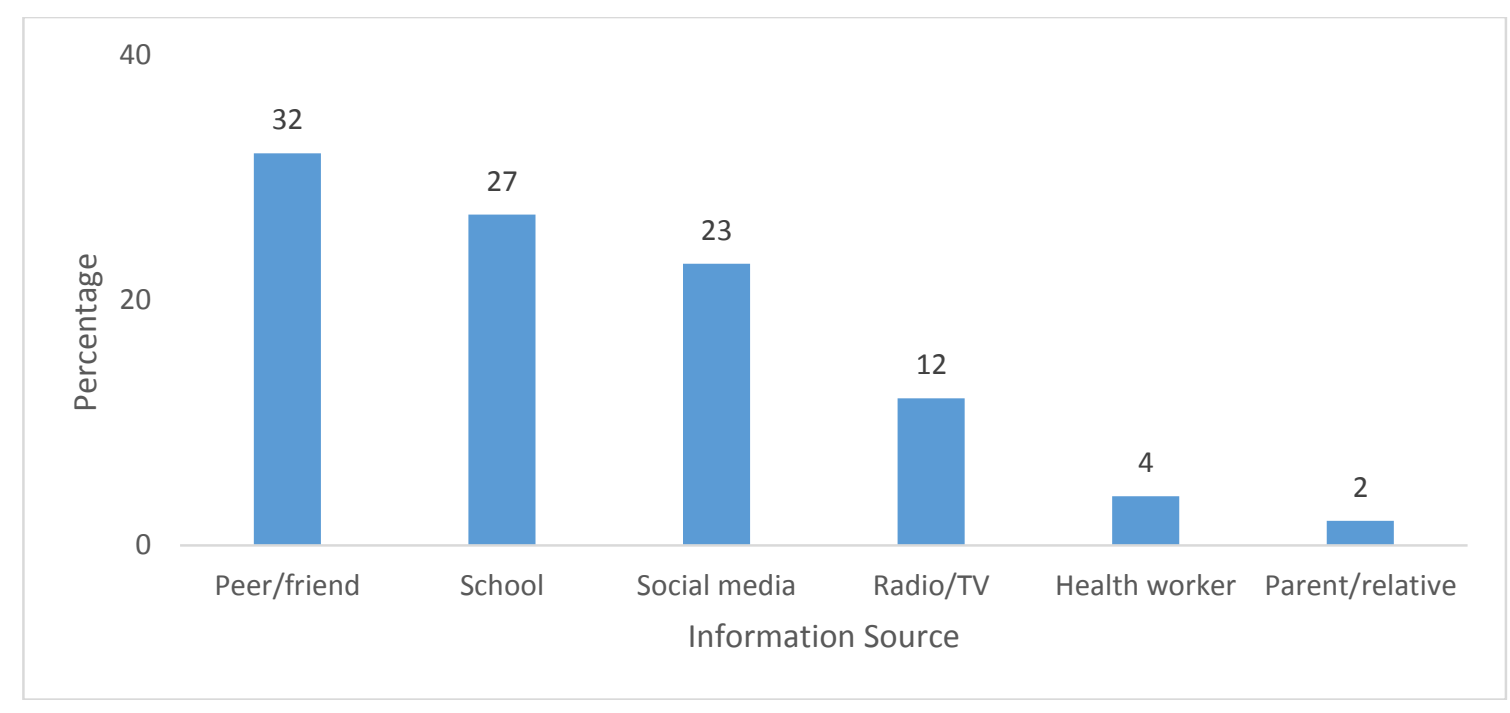

$\mathrm{N}=113$

Fig 1: Percentage distribution of the respondents' source of information about SRH

Knowledge on STI

The study observed that knowledge of risk factors associated with STI has impact on reproductive health of YPLWH. Participants were asked about their awareness on the risk factors associated with transmission of STIs. Findings observed that unprotected virginal sex was the commonly known risk factor associated with STI, $86 \%$. About $78 \%$, reported their awareness on multiple sexual partners as a risk factor for STI. It is interesting to note that, only $47 \%$, indicated their awareness on drug injection as a mode of STI transmission. Although YPLWH demonstrated reasonable awareness risks associated with STIs, findings from the qualitative data revealed that YPLWH are engaging in anal sex and oral sex with a belief that they are safe from STIs. Such beliefs are risk to their reproductive health. 


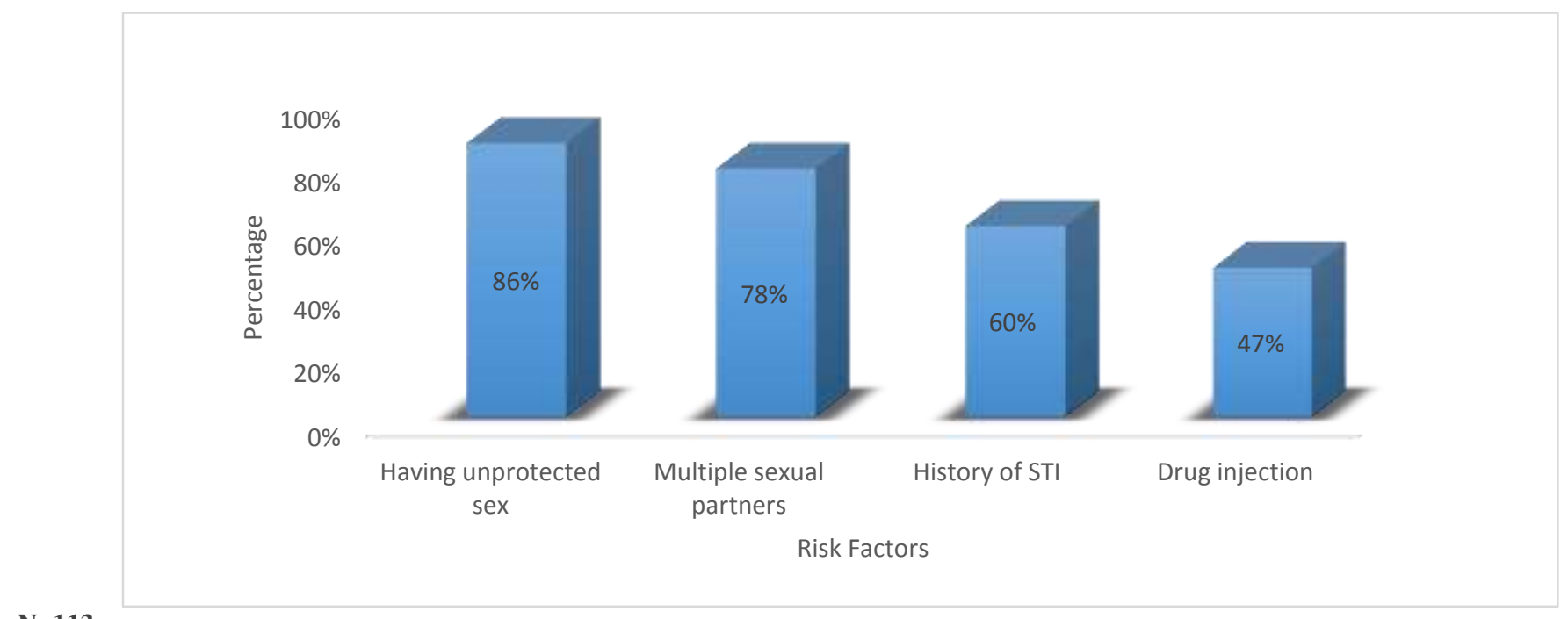

$\mathbf{N}=113$

Fig 2: Percentage distribution of the respondents' awareness risk factors associated with STI transmission

Respondents were further asked their knowledge about the general symptoms of STIs. Findings revealed that respondents within age group 15-17 years were less likely to be aware of symptoms of STI compared to older ages. Majority of respondents were aware of pain during urination, $15-17$ years $(23 \%), 18-20$ years $(41 \%)$ and $21-24$ years $(54 \%)$. However, awareness of lump on genitals and pain in the scrotum were less likely to be known among YPLWH. Findings from qualitative data revealed that swollen of testicles is common among adolescent boys, hence it would be difficult for them to know whether it will be an STI or not.

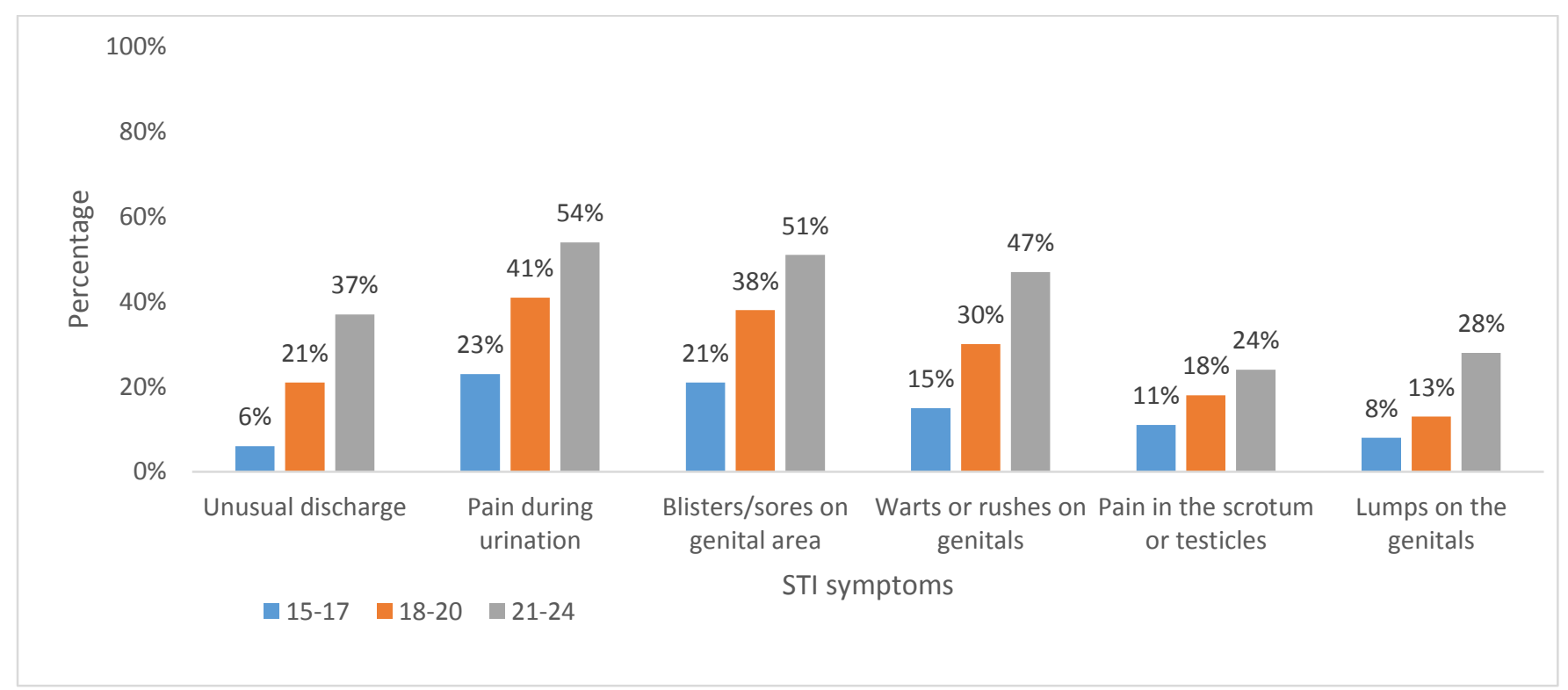

$\mathrm{N}=113$

Fig 3: Percentage distribution of the respondents' awareness of STI symptoms by age group

\section{Knowledge about Contraceptive}

Public health researchers have shown that knowledge on contraceptive methods is an important variable key to determine positive health outcome for YPLWH. In this current study, participants were asked whether they were aware of at least 5 contraceptive methods. Majority of participants, $58 \%$ reported that they were aware of at least contraceptive methods (Table 3). Further analysis established that young people's knowledge of modern contraceptives was associated with age, $(\mathrm{p}=0.012)$, sex $(\mathrm{p}=0.002)$ and marital status $(\mathrm{p}=0.030)$, religion $(\mathrm{p}=0.011)$ and level of education ( $\mathrm{p}=0.031)$. A significant relationship was observed between knowledge of contraceptive methods and age. For instance, 68\% respondents aged between 21-24 years reported awareness of contraceptives while only $46 \%$ those in age group $15-17$ years reported the same. While both males and females were aware of modern contraceptive methods, females were more likely, $65 \%$, to be aware of modern contraceptives. An intricate relationship was observed between marital status and knowledge of modern contraceptives. For example, $78 \%$ of the married/cohabiting respondents reported having knowledge about modern contraceptive method while only $48 \%$ of those who were never married reported the same. This can be attributed to the fact that married people were more exposed and already using contraceptive 
methods. It was observed during the FGDs, that unlike the married/cohabiting respondents, there are social barriers limiting unmarried young people to have access to sexual and reproductive health information. Note this remark from a young man in an FGD of 15-17 years and other participants also confirmed it:

"When we ask for condoms from community health workers, instead of giving me the condom they start interrogate you with questions that will make you lose all the confidence of coming back again. As young people we are not even expected to talk about sex..."

The analysis also observed a significant relationship between religion and contraceptive knowledge. Although all religions demonstrated knowledge about contraceptives, African Tradition reported the the least, $22 \%$. Note the following remark from a local herbalist from Chitungwiza community:

"My daughter, we have herbs for any type of disease, all these contraceptives you are talking about are made from herbs. I help a lot of young people with who want to do abortion or STI treatment. No need for them to go in public clinics and get embarrassed by health workers"

The analysis shows that the higher the education, the more knowledgeable an individual is about contraceptive methods. While $69 \%$ respondents with tertiary education, only $31 \%$ reported having awareness of modern contraceptive methods. Qualitative data revealed that schools play an important role in disseminating information on contraceptives. Hence, young people who have never been in school are more likely not to be knowledgeable about contraceptive methods. Note this remark from one of the young girls aged 21 during an in-depth interveiw:

"My peers who are going to school told me about long active contraceptive methods which have been introduced in family planning clinics. I only knew about birth control pill because 1 saw them from my aunt"

Social believes and values have direct impact on knowledge acquisition. Opinions from key informants revealed married people are more acceptable to seek contraceptive information than unmarried young people. Note a remark from one key informant:

"Contraceptives are meant for married people, allowing young people to access them before marriage will erode the social values that defines our African" (Female FGD, Chitungwiza)

Although there were social factors prohibiting YPLWH to know more about contraceptives, religious beliefs were commonly cited in FGDs for both males and females across all age groups.

\begin{tabular}{|c|c|c|}
\hline Background Variable & Percentage & P-Value \\
\hline \multicolumn{3}{|l|}{ Age } \\
\hline $15-17$ & 55.2 & 0.012 \\
\hline $18-20$ & 62.3 & \\
\hline $21-24$ & 68.0 & \\
\hline \multicolumn{3}{|l|}{ Sex } \\
\hline Female & 65.2 & 0.002 \\
\hline Male & 58.6 & \\
\hline \multicolumn{3}{|l|}{ Marital Status } \\
\hline Married/Cohabiting & 78.1 & 0.030 \\
\hline Never Married & 48.0 & \\
\hline Widowed & 55.5 & \\
\hline Divorced & 67.9 & \\
\hline \multicolumn{3}{|l|}{ Religion } \\
\hline Pentecostal & 56.3 & 0.041 \\
\hline Mainline & 54.0 & \\
\hline Catholic & 55.3 & \\
\hline Apostolic & 45.9 & \\
\hline Muslims & 33.3 & \\
\hline African Tradition & 21.9 & \\
\hline \multicolumn{3}{|l|}{ Level of Education } \\
\hline None & 30.7 & 0.031 \\
\hline Primary Education & 47.5 & \\
\hline Secondary Education & 58.9 & \\
\hline High School Education & 65.1 & \\
\hline Tertiary & 69.4 & \\
\hline \multicolumn{3}{|l|}{ Employment } \\
\hline Full-Time Formal job & 71.1 & $0.551(\mathrm{NS}$ \\
\hline Domestic job & 46.1 & \\
\hline Entrepreneurship & 69.5 & \\
\hline Unemployed & 47.8 & \\
\hline \multicolumn{3}{|l|}{ Income } \\
\hline Less than $\$ 100$ & 66.0 & $0.581(\mathrm{NS})$ \\
\hline$\$ 101$ to 250 & 79.1 & \\
\hline$\$ 251$ to $\$ 500$ & 87.4 & \\
\hline Above $\$ 500$ & 94.1 & \\
\hline Total & 57.9 & \\
\hline
\end{tabular}

$\mathrm{N}=113$

Table 3: Percentage distribution of the respondents' knowledge on modern contraceptive methods by background variables 
Knowledge about risks associated with pregnancy and childbearing

To determine the knowledge of respondents on pregnancy and childbearing, young people were asked whether they were aware of pregnancy and the risk associated with pregnancy in HIV positive women. Although respondents demonstrated some awareness of risk associated with pregnancy, the knowledge was very low, $42 \%$, (Table 4). A positive association was observed between awareness of the risks associated with pregnancy and age $(\mathrm{p}=0.001)$, sex $(\mathrm{p}=0.022)$, marital status $(0.0400)$, religion $(=0.030)$ and level of education $(\mathrm{p}=0.00)$. For instance, while $45 \%$ respondents aged 21-24 years reported knowledge about pregnancy and risks associated to it, only 17\% aged between 15-17 years reported the same. Study observed that married women are more likely, $69 \%$, to be knowledgeable about pregnancy and childbearing. Those who never married reported less than half; $47 \%$ awareness of pregnancy and associated risks. During the qualitative finding it was observed that married women have experience on pregnancy and childbearing than unmarried women. Note this remark from a key informant:

"Although we encourage YPLWH to visit their local family planning clinics, they do not visit. And because they are not aware of what should be done when one gets pregnant, they always present their pregnancy very late, which complicate the effectiveness of PMTCT intervention."

The analysis also shows that there is a significant relationship between level of education and knowledge on pregnancy and childbearing. For instance, while $67 \%$ of respondents who attained tertiary education reported that they have knowledge about pregnancy and childbearing, only $23 \%$ who never attained education reported the same. While knowledge on pregnancy was common among all religions, Pentecostals were more likely, to be knowledgeable about pregnancy and childbearing than others. Although churches resist education on contraceptives for young people, Pentecostals churches participate in health commemoration days like World AIDS days. One key informant from a Pentecostal church gave the following remarks:

"Having considered the health challenges affecting our believers, now we are also participating in health commemoration day like the World AIDS day, Cancer Day and others. On such days we invite health experts to teach congregants about health issues including reproductive health." (Church elder; Waterfalls)

\begin{tabular}{|c|c|c|}
\hline Background Variable & Percentage & P-Value \\
\hline \multicolumn{3}{|l|}{ Age } \\
\hline $15-17$ & 17.2 & 0.001 \\
\hline $18-20$ & 31.9 & \\
\hline $21-24$ & 44.5 & \\
\hline \multicolumn{3}{|l|}{ Sex } \\
\hline Female & 56.1 & 0.022 \\
\hline Male & 40.3 & \\
\hline \multicolumn{3}{|l|}{ Marital Status } \\
\hline Married/Cohabiting & 69.1 & 0.040 \\
\hline Never Married & 47.3 & \\
\hline Widowed & 50.4 & \\
\hline Divorced & 54.6 & \\
\hline \multicolumn{3}{|l|}{ Religion } \\
\hline Pentecostal & 53.3 & 0.031 \\
\hline Mainline & 52.0 & \\
\hline Catholic & 49.6 & \\
\hline Apostolic & 43.0 & \\
\hline Muslims & 35.8 & \\
\hline African Tradition & 31.2 & \\
\hline \multicolumn{3}{|l|}{ Level of Education } \\
\hline None & 23.4 & 0.000 \\
\hline Primary Education & 49.3 & \\
\hline Secondary Education & 53.2 & \\
\hline High School Education & 64.0 & \\
\hline Tertiary & 66.5 & \\
\hline \multicolumn{3}{|l|}{ Employment } \\
\hline Full-Time Formal job & 51.1 & $0.521(\mathrm{NS})$ \\
\hline Domestic job & 55.1 & \\
\hline Entrepreneurship & 53.5 & \\
\hline Unemployed & 55.8 & \\
\hline \multicolumn{3}{|l|}{ Income } \\
\hline No income & 54.6 & \\
\hline Less than $\$ 100$ & 56.0 & $0.251(\mathrm{NS})$ \\
\hline$\$ 101$ to 250 & 59.1 & \\
\hline$\$ 251$ to $\$ 500$ & 57.4 & \\
\hline Above $\$ 500$ & 44.1 & \\
\hline Total & 47.0 & \\
\hline
\end{tabular}

$\mathrm{N}=\mathbf{1 1 3}$ 
Knowledge about risks associated with pregnancy and childbearing

Participants were asked their awareness of the risk associated with pregnancy. Although participants demonstrated some level of awareness on risks associated with pregnancy, findings showed that younger ages (15-17 years) had low knowledge (Table 4). The findings observed that risk of infecting an unborn child was commonly reported across all age groups, 45\% (15-17years), 55\% (18-24) and 69\% (21-24 years). Qualitative data revealed that HIV is now a critical course in the school curricula, young people have opportunity to know the interventions for
HIV transmission. Note the following remark from one participant during the FGD:

"I learn risk of transmission HIV at school and PMTCT is one of the risks."

The findings also observed that participants were aware of the risk of high blood pressure among pregnant women, in age group 15-17 years (38\%), $18-20$ years $(48 \%)$ and $21-24$ years $(55 \%)$. However, anemia was the least known risk factor with $13 \%$ (15-17 years), 17\%, 18-20 years and 31\% (21-24 years).

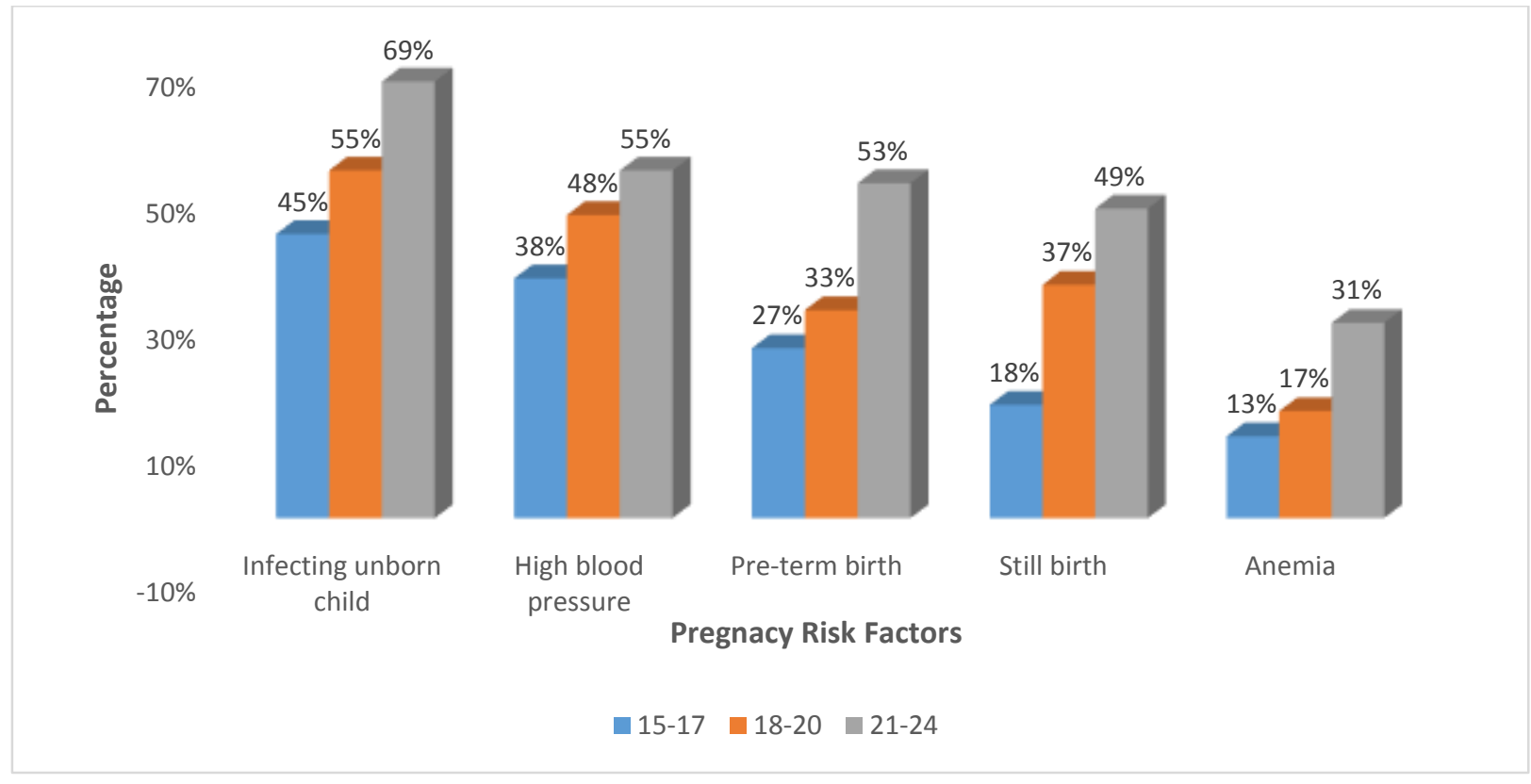

$\mathbf{N}=\mathbf{1 1 3}$

Fig 4: Percentage distribution of the respondents' knowledge on risk factors associated with pregnancy

\section{Discussion of Findings}

Findings of this study concluded that SRH knowledge among young people with HIV was low. For example, $47 \%$ of the respondents reported that they were aware of SRH. This is in sync with the studies done in America, California, and Denmark by Sarna et al (2005), Moultre et al., (2011), Jerman and Lissues (2015), where YPLWH's knowledge about SRH among black African young women with HIV was ranging between $52 \%$ to $60 \%$, which was low considering the quality of services in those countries. However, in Zimbabwe, the findings validate the findings by UNFPA (2015) where $48 \%$ of HIV positive young people aged between 15-24 years had comprehensive knowledge about SRH. It is important to note that most unmarried YPLWH reported relatively low knowledge on sexual and reproductive. The finding is valid given our cultural and religious values where it is taboo for young unmarried people to seek information on family planning, contraceptives, sex and other SRH related. In addition, YPLWH fear to be seen seeking SRH services because their think everyone will know their status and they will lose social relationships.

Study findings observed that most of YPLWH are reliant on their peers, schools and social media for SRH information. For instance, the study observed that about $32 \%$ of participants get information from peers, $27 \%$ access from school and $23 \%$ accessed from social media. This observation was also observed in a study by Owusu and Abane (2016) in Ghana, where $60 \%$ of young people access SRH information from peers and social media. Although parents are expected to educate their children on
$\mathrm{SRH}$, the findings observed that only $2 \%$ received SRH information from their parents. The findings are corroborating studies conducted in Kenya by Karongo (2015) where talking about sex is often scowled by parents, religious adherents, and traditionalists, making the environment unfriendly for YPLWH. Consistently, findings revealed that even though health workers are the most reliable source of information, findings revealed that only $4 \%$ accessed information from them. This concurs with studies conducted in Malawi by Batasara (2013) where only $13 \%$ of young people accessed SRH information from health centers. Similarly, studies conducted in Zimbabwe, by Mhloyi et al (2016) corroborated with the study findings that YPLWH prefer to get information from friends and social media. However, many studies have shown that these preferred may have information which is harmful to young people.

This study observed that, YPLWH have limited knowledge about pregnancy and childbearing. For instance, $47 \%$ of respondents demonstrated knowledge about pregnancy and childbearing. Similar findings were observed in Kenya by Mbungua (2015) in a study on adolescent reproductive health where $54 \%$ of HIV positive young women (19-24 years) reported no intentions of having children because the fear giving birth to an HIV positive baby. Ideally, HIV positive people should get professional health advise when they plan to become pregnant. However, the study observed that pregnancy and childbearing is acceptable in a marriage or union as such early PMTCT initiation is a challenge among young women who are not married. This may have an effect on transmitting the virus to an unborn child. These findings were mirrored in other studies conducted in Philippine by Rodgers (2014) 
where $25 \%$ of late presenting HIV pregnant mothers were aged 15-24 years. Similarly, Ontorio (2015) in Ethiopia and Katzenstein (2016) in Nigeria observed that missing doctor' review appointments and nonadherence is more prominent among pregnant young mothers aged 15-20 years. In Zimbabwe, statistics from Harare Family Care Unit reported $33 \%$ of perinatal infections were among young mothers aged 15-24 years (IMPAACT;2016). These results pointed a knowledge gap on pregnancy; hence, the study recommend that HIV and SRH programs for YPLWH should not be treated as separate interventions. Youth friendly corners must be equipped with supporting services for both SRH, HIV acre and treatment as well as mental health not only an ART clinic where young people come to collect drugs and leave.

Although the participants generally demonstrated awareness on STI transmission, their knowledge is found to be incomplete. The study demonstrated that younger ages have limited knowledge about symptoms of STIs. For instance, only 6\% respondents aged 15-17 years knew that unusual discharge is a symptom of STI and only $8 \%$ of respondents in the same age group showed their awareness of lumps on genital organs as a symptom of STI. The findings resonate with findings from a clinical study conducted in the United States by Durker (2015) where 60\% of HIV positive men who were diagnosed with STIs failed to explain how STIs the symptoms they observed before diagnosis. A study conducted in Kenya by Tsegaye (2016) demonstrated that only a quarter of HIV positive young people demonstrated knowledge about STIs. In Zimbabwe, although HIV awareness is now universal, prevalence of STI remains high with limited STI knowledge among youths. According to ZIMSTATS, $12 \%$ of youths ever had STI against $8 \%$ reported in older population. This study, however, recommend that STI education and awareness should be imbedded in the HIV care and treatment as well as in the school education curricular.

\section{Conclusions and Recommendations}

Findings from this study highlighted that SRH knowledge increase the desire to have more information and accessing available SRH services among young people with HIV. It was also observed that source of information direct impact on knowledge, attitude, and practice. Although health workers are best placed to disseminate SRH information, the study observed that YPLWH preferred to access information from peers, parents, and community health workers. Although contraceptive use was reported among young people, younger ages were less likely to utilize contraceptives because of socio-cultural and structural barriers. Findings from this study reported that places to get contraceptive has a bearing to access and utilization of contraceptives. Community health worker was the most cited convenient and preferred place for YPLWH to access contraceptives. In addition, YPLWH expressed the desire to have children, but they fear to give birth to HIV positive children and there were socio-cultural factors which may influence them to commit unsafe abortion. Hence, there need for educative programs to increase SRH knowledge for young people living with HIV for them to make knowledgeable decision. It is also important for academia research findings to be disseminated to communities to demystify some perceptions and believes which may be proven wrong in public health. There is also need for MoHCC to improve service delivery system for it to be youth friendly and promote privacy and confidentiality. Unless the issue of knowledge, accessibility, and affordability of SRH services to YPLWH is not addressed, national efforts to achieve the positive sexual and reproductive health outcomes among adolescents and young people will continue to be a dream.

\section{Recommendations}

Consideration the study findings, the following are proposed recommendations to the improvement of programs and intervention which aim to address sexual and reproductive health issues among young people living with HIV.

- Teachers should be given enough skills on sexual and reproductive health and counselling for them to be able to provide support to YPLWH and disseminate correct and accurate information

- MoHCC should enhance psychosocial support which is linked to mental health services

- MoHCC should continue to empower YPLWH for them to be able to disclose their status to their partners and also to ask their partners' status before sex

- There should be a continuum of care starting from the family, church and ending in public institutions

- Government should upgrade youth friendly corners and equip them with appropriate services needed by HIV positive young people

- MoHCC should continue to capacitate health care workers on confidentiality so that young people may be able to privately access contraceptive and other SRH services

\section{Further research}

The study is a whistleblower to the government, communities and researchers in understanding the sexual and reproductive issues that are affecting young people living with HIV. Although many researches have pointed to a gamut of sexual and reproductive health challenges faced by young people, there is dearth literature to understand the underlying factors. This has resulted in poor response to SRH needs of HIV positive young people.

Since the findings were gathered from two locations and focusing only on young people who were accessing ART services at four health centers, there is need for further research with bigger coverage to establish the SRH challenges affecting young people living with HIV both on ARV treatment and those who are not on treatment. This may assist policy makers, health service providers and communities to provide relevant support needed for young people to realize their reproductive health goals in a health and safe manner.

\section{References}

1. Macintrye, H. (2011) Beyond Sugar Daddies: Intergenerational sex and AIDS in urban Zimbabwe. AIDS and Behaviour. 15 (6): 1275-1282.

2. Sosley L and Mhloyi, M. (1994) Fertility Levels and Trends in Zimbabwe. African E-journals.

3. Mucheri, T., Makunika, N., Nyoni, T., Mose, N., Nhliziyo, D., \& Manyange, L. (2021). Knowledge of HIV Prevention Methods among Adolescents. Journal of Medical and Dental Science Research, 8(6), 72-80.

4. UNAIDS. Joint United Nations Programme on HIV/AIDS: UNAIDS DATA 2017 reference, 2018FHAPCO, GRHAPCO, UNAIDS. Synthesis of the HIV Epidemic and Response in Gambella. 2014

5. Salami, N, Moyo, S. and Rusinga, O. (2017) Contraceptives: Adolescents' Knowledge, Attitudes and Practices. A Case Study of Rural Mhondoro-Ngezi District, Zimbabwe. African Journal of Reproductive Health

6. UNICEF, UNAIDS, PEPFAR (2006) Africa's orphaned and vulnerable generations: children affected by AIDS.

7. Remez, L. Woog, V. and Mhloyi M. (2016) Sexual and Reproductive Health Needs of Adolescents in Zimbabwe. 21(6): 725_731

8. Mhloyi, M., Terry, P. E. and Masvaure, T. (2006) An examination of knowledge, attitudes and practices related to HIV/AIDS 
prevention in Zimbabwean university students: Comparing intervention program participants and non-participants. International Journal of Infectious Diseases, 10, 38-46

Tesfaye, K. R., Bibeau, D., Steckler, A., \&Glanz, K. (1988) An ecological perspective on health promotion programs.Health Education \&Behavior, 15(4), 351- 377.

9. Makunika, N., \& Manyange, L. (2020). Determinants of HIV Prevention amongst Adolescents in Zimbabwe: The Case of Dzivarasekwa, Harare. International Journal of Sexual and Reproductive Health Care, 3(1), 051-060.
10. Obare, F., Anke van der K. et al. (2010) HIV-positive adolescents in Kenya. Access to sexual and reproductive health services. Bulletin 393, Amsterdam, KIT Publishers.

11. Manyange, L., Mucheri, T., Nyoni, T., Makunika, N., \& Mose, N. (2021). Contraceptive use among Young Adults in Zimbabwe, Questionnaire Study. South Asian Journal of Social Studies and Economics, 37-47.

12. Sosley L and Mhloyi, M. (1994) Fertility Levels and Trends in Zimbabwe. African E-journals.
DOI: $10.31579 / 2642-9756 / 091$
Ready to submit your research? Choose Auctores and benefit from:

$>$ fast, convenient online submission

$>$ rigorous peer review by experienced research in your field

$>$ rapid publication on acceptance

$>$ authors retain copyrights

$>$ unique DOI for all articles

$>$ immediate, unrestricted online access

At Auctores, research is always in progress.

Learn more auctoresonline.org/journals/women-health-care-and-issues 